open@ACcess

Authors' contribution:

A) conception and design of the study

B) acquisition of data

C) analysis and interpretation of data

D) manuscript preparation

E) obtaining funding

Received: 27.05 .2021

Accepted: 16.06 .2021

\section{Self-assessment of football referees on their educational influence on children aged 9-12 during a sports competition}

\author{
Katarzyna Płoszaj*A-D (iD, Wiesław Firek ${ }^{\text {A-E }}$ iD \\ Józef Pitsudski University of Physical Education, Warsaw, Poland
}

*Correspondence: Katarzyna Płoszaj, ul. Jana III Sobieskiego 112/42, 00-764 Warszawa; email: katarzyna.ploszaj@awf.edu.pl

\begin{abstract}
Proper use of the educational potential of sports depends on the entities organizing children's sports competitions (coaches, parents, referees). Particularly important is their awareness of the purposefulness and legitimacy of actions taken. Numerous studies have been devoted to the role of the coach and parents in providing children and young people with positive sporting experiences. In contrast, the referee has often been overlooked. The behavior of the referees during the match is also important for young players. Assuming that referee-player interactions have a major contribution to educational influence, the purpose of this study was to explore the opinions of soccer referees refereeing matches of children aged 9 to 12 years about their interactions with players in terms of emotional support, game organization, and instructional support. It was also decided to verify whether referees' self-assessment of their educational function is influenced by experience. The research was conducted among 116 referees licensed by Mazovian Football Association who referee matches of children aged 9-12 years (Orliki and Młodziki categories) in the Masovian Voivodeship in Poland. To assess the referee-players educational interaction, a questionnaire survey was developed. These interactions are present in three domains: emotional support, game organization and instructional support. The results showed significant differences between referees' self-assessments in the three domains. Referees rated their educational interactions with players higher in the domain of emotional support than the instructional support. Moreover, the results indicated that there was no differences in the referees' self-assessment between the groups distinguished by more experienced in the domains of emotional support and game organization, while less experienced referees rated the quality of their educational interactions in the instructional support domain higher than those more experienced. The main conclusion of the research is the postulate to introduce pedagogical and psychological issues into the referee training.
\end{abstract}

Key words: Referee, football, youth sport, referee-players interactions, educational practice

\title{
Introduction
}

Sporting activities intersect in the social space with other areas of human activities. Sport is used as a 'global language' to promote international awareness and cross-cultural understanding (Tiessen 2011). There is a growing interest in how sport can support societal missions like promoting peace (Keim, 2012; Galily, Leitner \& Shimion, 2012), shaping national and cultural identities or social justice (Schinke \& Hanrahan, 2012). Giulianotti and 
Numerato (2019) point to the complex relationships between sport consumption and sociological factors. Many researchers study participation in the sport of youth (Birchwood, Roberts \& Pollock, 2008) and family (Wheeler, 2012; Lenartowicz, 2016) because of their social origin.

The value of sport is usually measured by its potential to positively influence other areas of social life, enhancing the desired changes and limiting undesirable phenomena (Lenartowicz \& Mosz, 2018). However, Theodoulides (2003) noted, that we assume too hastily, that sports values are "caught not taught". To achieve socially useful goals we have to define clear teaching and learning strategies ('taught'). If we take 'caught' philosophy, we must acknowledge, that negative and positive behaviours in sport are just as easily acquired. The educational potential of a sports event does not result from the essence of the sport itself, because it is not autonomous from the outside world (Lenartowicz \& Mosz, 2018). It can be said that socially accepted and desired values can be reflected in sport. Sport is only a tool for socializing children to participate in culture, including sports culture. For educators, the stadium is not only a material space dedicated to sport, but a space that can be instrumentalized for the purposes of implementing educational ideals. Proper use of the educational potential of sports depends on the entities organizing children's sports competitions (coaches, parents, referees). Particularly important is their awareness of the purposefulness and legitimacy of actions taken. Numerous studies have been devoted to the role of the coach (Mageau \& Vallerand, 2003; Horn, 2008; Thompson, 2013). The problem of parenting in sport is also widely discussed (Domingues \& Gonçalves, 2013; Hardwood \& Knight, 2015; Lenartowicz 2016; Romani, 2019; Strandbu, Stefensen, Smette, \& Sandvik, 2019).

Nowadays, sport plays an important role in the educational experience of youth (Telama et al., 2005; Wheeler \& Green, 2014). Wheeler and Green (2014) emphasized that the parents recognize the importance and the benefits of sports, not only related to the development of physical fitness and skills. The list of parents' expectations regarding the benefits of playing sports by their children is very long. The list of these expectations automatically becomes a challenge for the coaches and judges. For parents, children's participation in sport is an investment that is expected to bring specific benefits. Nowadays, the „sports market” resembles the „education market” (Wheeler \& Green, 2014). With increasing requirements and changing of parents' expectations, the competencies of coaches and referees should also change.

Sport doesn't always bring positive educational experiences to young players (Jones, 2005). Therefore, researchers postulate that approaches aimed at building a positive climate should be implemented in children's sports (Bengoechea, Strean, \& Williams, 2004; Cronin \& Allen, 2015; Light \& Harvey, 2015). Most experts further agree that the adults involved in children's sport should promote and support positive behavior in young athletes. Proper behavior management is fundamental to achieving educational objectives and organizing quality sporting events (Lavay, French, \& Henderson 2016). Furthermore, the benefits of instructing young athletes have been discussed by, among others, Berkowitz and Grych (1998), and Andersson (2019). Płoszaj et al. (2020) defined instructional support as a way to convey the rules and values of sport.

Coaches and parents are widely analysed and discussed societal groups. In contrast, the referee has been often overlooked (Andersson, 2019; Cipriano et al., 2020). This may be due to the various roles of referees in different sports (MacMahon et al., 2015). MacMahon and Plessner (2008) took into account the different natures of individual sports and distinguished three types of referees. Ones who 1. interact; 2 . react; and 3. evaluate. The present study focuses on soccer referees who interact with the players in numerous ways during a match..

The behavior of the referees during the match is also important for young players (Andersson, 2019). Therefore, in addition to their supervisory and control tasks, they should also perform an educational function (Arthur-Banning, Paisley \& Wells, 2007; Andersson, 2019). Isidori et al. (2012) argue that referees are usually unaware of the complexity of the responsibilities that come with this function. Lehman and Reifman (2001) point out that referees are present on the field to not only direct the players but also to manage the behaviour of all the other participants of sports event. They should have skills to alleviate social tensions and negative athlete behaviors (Friman, Nyberg \& Norlander, 2004) and avoid being the source of them (Fruchart \& Carton, 2012). The referees themselves acknowledge that specific knowledge is required to manage player behavior (Slack, Maynard, Butt \& Olusoga, 2013). The desired competence of the referees is so that they monitor the emotional states of the players and respond appropriately to their needs (Dosseville, Laborde, \& Berniern, 2014). Therefore, it is currently postulated that the referees should ensure high-quality interactions that are conducive to building a positive climate with the players much more often. This should be even more important in youth sport as it facilitates achieving educational aims (Boxer, Stuart \& Ebbeck, 1995; Arthur-Banning, Paisley \& Wells, 2007).

Nowadays, pedagogues argue that high-quality teacher-pupil interactions have a major role in contributing to the cognitive, social, emotional, moral, and physical development of students (Pianta, Hamre \& Mintz, 2012). 
The results of empirical studies confirm that classroom interactions based on a positive climate, and appropriate instructional and organizational support related to effective behavior management lead to better learning outcomes of students, increase their commitment and motivation to work, shape socially desirable attitudes, and develop selfcontrol skills. The quality of these interactions depends primarily on the adults functioning in the school environment (Woolfolk Hoy \& Weinstein, 2006; Collins \& Barcelona, 2018).

The requirements for teachers to build high-quality interactions with students can also be transferred to other settings where intentional educational activities are implemented. If appropriate emotional support, instructional support, and classroom organization in school yield positive results (Pianta et al., 2002), the actions taken in these three domains can be translated into educational measures in sport (Fry, 2010; Achrati, Manning, McDonnell, Harris \& DiPietro, 2015; Côté \& Hancock, 2016).

Assuming that referee-player interactions have a major contribution to educational influence, the purpose of this study was to explore the opinions of soccer referees refereeing matches of children aged 9 to 12 years about their interactions with players in terms of emotional support, game organization, and instructional support. It was also decided to verify whether referees' self-assessment of their educational function is influenced by experience. Therefore, the following hypothesis was formulated: experienced referees rate the performance of the educational function in children and youth sport higher than referees with less experience. For the purpose of the study, it was assumed that an experienced referee is a person who has been refereeing for 4 years or more. Taking into account the referee training programs, which in Poland does not include pedagogy and psychology while focusing mainly on teaching the rules of the game, their interpretation, and the gestures used in refereeing, the second hypothesis was formulated: referees self-assess their competence in game organization better than that in emotional support and instructional support.

The presented research ties in with the goals and objectives of sports education aimed at finding principles, methods, and practices to improve the quality of educational interactions in sports settings by building appropriate coach-athlete, referee-athlete, and parent-child interactions (Lavay, French \& Henderson, 2016). The results of the study can be used by the refereeing departments of soccer associations during training and also to develop and introduce an educational aspect into the evaluation process of their work.

\section{Material and methods}

\section{Participants}

The research was conducted among 116 referees licensed by Mazovian Football Association who referee matches of children (Orliki and Młodziki categories) in the Masovian Voivodeship in Poland. The referees surveyed included 8 women and 108 men, which reflects the general gender ratio among referees from this regional association. Over half of the referees were 19-24 years old, and $41 \%$ were older than 24 . The smallest group of referees $(8 \%)$ was under the age of 19 . The referees differed in their levels of referee licenses. The most numerous group were referees of the lowest classes of games: B Class (32\%) and A Class (24\%). The other referees held the following licenses: Regional League (15\%), the IV League/III League (6\%), Assistant (12\%), and Disposition (11\%). More than half of the referees $(61 \%)$ had at least four years of refereeing experience; the remaining referees were less experienced $(<4$ years).

\section{Measures}

For the purposes of the study, a survey questionnaire was developed, based on the Referee-Players Interactions Assessment Scoring System direct observation tool. The R-PIASS tool is used to assess the quality of the interactions between the referee and the players aged 9 to 12 years. This tool is based on the assumption that referee-players interactions are the primary mechanism for referee's educational influence in children and youth sport. These interactions are present in six dimensions: positive climate, responsiveness, behavior management, proficiency, instructing, and communicating. These dimensions comprise three domains. The first domain, Emotional support, is formed by the dimensions of positive climate and responsiveness. The second domain called Game organization contains the dimensions of behavior management and proficiency. The dimensions of instructing and communicating make up the Instructional support domain (Płoszaj et al., 2020).

The questionnaire survey Self-assessment of educational influence of referees in sports competition of children aged 9-12 was designed based on all dimensions and domains of the R-PIASS tool. This made it possible to compare the referees' self-assessments with the results of their direct observations conducted in the study by Firek et al. 
(2020). The questionnaire consisted of 25 statements assessed on a 5-point Likert scale. Statements 1-5 referred to indicators highlighted in the positive climate dimension, 6-9 to indicators of the responsiveness dimension. The remaining groups of items 10-13,14-17, 18-21, and 22-25 referred to the dimensions of behavior management, proficiency, instructing, and communicating, respectively. The method of constructing statements based on the RPIASS tool is presented in Table 1. Respondents were asked to comment on the statements included in the survey using the following scale: 1 - I totally disagree; 2 - I disagree; 3 - It's hard to say; 4 - I agree; 5 - I totally agree. The higher the score, the more often the referee declared certain behavior on the field. In negatively worded statements, the scoring was reversed.

Table 1. Examples of how statements were constructed based on the indicators of each dimension of the R-PIASS tool referred to by referees

\begin{tabular}{|c|c|c|c|}
\hline \multirow[b]{2}{*}{ Domains } & \multirow[b]{2}{*}{ Dimension } & \multicolumn{2}{|c|}{ Research tools } \\
\hline & & $\begin{array}{l}\text { Referee-Players Interactions Assessment } \\
\text { Scoring System (Płoszaj et al., 2020) }\end{array}$ & $\begin{array}{l}\text { Self-assessment of the educational influence of } \\
\text { soccer referees in sports competition of children } \\
\text { aged } 9-12\end{array}$ \\
\hline \multirow{2}{*}{$\begin{array}{l}\text { Emotional } \\
\text { support }\end{array}$} & Positive climate & $\begin{array}{l}\text { Example indicator: } \\
\text { Enthusiasm (smiling, engagement, positive } \\
\text { affective reaction) }\end{array}$ & $\begin{array}{l}\text { During the match, I am smiling and enthusiastic } \\
\text { about my responsibilities. }\end{array}$ \\
\hline & Sensitivity & $\begin{array}{l}\text { Example indicator: } \\
\text { Solving problems }\end{array}$ & $\begin{array}{l}\text { I always manage to quickly solve a problem that } \\
\text { I notice on the pitch. }\end{array}$ \\
\hline \multirow{2}{*}{$\begin{array}{l}\text { Game } \\
\text { organization }\end{array}$} & $\begin{array}{l}\text { Behavior } \\
\text { management }\end{array}$ & $\begin{array}{l}\text { Example indicator: } \\
\text { Redirecting negative behavior }\end{array}$ & $\begin{array}{l}\text { I use various techniques to redirect negative } \\
\text { behavior on the field. }\end{array}$ \\
\hline & Proficiency & $\begin{array}{l}\text { Example indicator: } \\
\text { Referee preparation (knowledge and skills, } \\
\text { referee equipment) }\end{array}$ & $\begin{array}{l}\text { When I referee I have the proper uniform and all } \\
\text { the necessary pieces of equipment. }\end{array}$ \\
\hline \multirow{2}{*}{$\begin{array}{l}\text { Instructional } \\
\text { support }\end{array}$} & Instructing & $\begin{array}{l}\text { Example indicator: } \\
\text { Communicating the game rules and teaching the } \\
\text { value of sport (clear and precise citation of game } \\
\text { rules, effective explanation, and instruction) }\end{array}$ & $\begin{array}{l}\text { While refereeing, I give the players instructions } \\
\text { on the rules of the game or help with their } \\
\text { interpretation. }\end{array}$ \\
\hline & Communicating & $\begin{array}{l}\text { Example indicator: } \\
\text { One-way communication techniques (decision } \\
\text { communication) }\end{array}$ & $\begin{array}{l}\text { While refereeing, I explain my decisions to the } \\
\text { players. }\end{array}$ \\
\hline
\end{tabular}

\section{Procedures}

The research was approved by the Research Bioethics Commission of the Józef Piłsudski University of Physical Education in Warsaw (SKE 01-10-2020). The survey questionnaire for referees was shared on Facebook in the closed group Obsada Wydziat Sędziowski Warszawa and was active from 15 April to 8 May 2020. The referees were informed about the purpose of the survey and asked for their consent. Furthermore, they were informed about their voluntary participation in the research, their anonymity, how their data would be stored and processed, and the possibility of withdrawing their consent at any time.

\section{Analytic strategy}

The results were compiled using MS Excel and IBM SPSS Statistics 2018 (IBM Corp., Armonk, NY, USA). Basic methods are used such as arithmetic mean, median, skewness, kurtosis, standard deviation, percentages, etc. to describe and evaluate the data. . The Shapiro-Wilk test was used to test normality. To determine the significance The Mann-Whitney U tests, Friedman's ANOVA and then Wilcoxon's signed-rank tests were used. The internal consistency of the tool was examined using Cronbach's alpha coefficient. The significance level for all analyses was set at 0.05 . 


\section{Results}

Table 2 below shows the extent to which referees agree with the statements concerning their interactions with the players in all six dimensions.

Table 2. The referees' self-assessments of their educational interactions with players $(n=116)$

\begin{tabular}{lcccccc}
\hline & Mean & Median & SD & Skewness & Kurtosis & Shapiro-Wilk p \\
\hline Positive climate & 3.26 & 3.33 & 0.67 & -0.26 & -0.36 & 0.117 \\
Sensitivity & 4.03 & 4.00 & 0.60 & -0.81 & 1.25 & $<001$ \\
Behavior management & 3.42 & 3.50 & 0.64 & -0.14 & -0.29 & 0.076 \\
Proficiency & 3.69 & 3.75 & 0.64 & -0.04 & -0.34 & 0.065 \\
Instructing & 3.45 & 3.50 & 0.82 & 0.17 & -0.63 & 0.016 \\
Communicating & 3.42 & 3.50 & 0.62 & -0.22 & -0.44 & 0.001 \\
\hline
\end{tabular}

Based on the test $(\mathrm{Chi}=11.103 ; \mathrm{p}=0.004)$, significant differences were observed in the self-assessment of referees in different dimensions of their educational function. In the next step, the Wilcoxon test for two dependent pairs was used to identify the dimensions between which these differences are observed. The test results showed that the differences were insignificant for pairs: positive climate-communicating $(\mathrm{Z}=-1.828 ; \mathrm{p}>0.05)$; behavior management-instructing $(Z=-0.272 ; p>0.05)$; behavior management-communicating $(Z=0.048 ; p>0.05)$ and communicating-instructing $(\mathrm{Z}=0.096 ; \mathrm{p}>0.05)$. For the remaining pairs, the differences were statistically significant. Referees rated themselves highest on the dimension of responsiveness ( $\bar{x}=4.03$ on a five-point scale). Respondents declared that they actively monitored the situation on the field for children's emotional, social, cognitive, and health needs and that they responded quickly to observed problems, which they usually managed to resolve, although this was not always the case. The second highest-rated dimension was proficiency. Almost half of the respondents declared that when they refereed, the game was usually or always smooth and there were no unnecessary interruptions. Almost three-quarters replied that it did not happen to them that after the whistle, the players did not know what to do. The other referees assessed themselves lower in this aspect. The average assessment of this dimension was raised by the declaration of almost all the referees that they always had the appropriate referee uniform and all necessary referee attributes. The average was lowered by the statement of almost half of the respondents that there were times when coaches, players, or parents rightly pointed out to them that they misinterpreted the rules of the game, which is an indicator of low proficiency of referees in performing their duties. Referees rated themselves lowest on the positive climate dimension, although a score of 3.26 on a five-point scale is an average result. Referees declared that they were unlikely to be in physical proximity with the players and only half of them considered themselves to be a person to be turned to for support. The vast majority of respondents declared that they were smiling and enthusiastic during the match and that they gave positive comments to the players if they did something well. Referees rated themselves at a similar level (3.42 to 3.45) on the other dimensions of educational interactions with young athletes. In the dimension of behavior management, the majority of the referees surveyed (56.03\%) reported communicating their expectations of behavior on the field to the players before the match. Nearly $90 \%$ responded that they tried to prevent fouls or other player misconduct with verbal messages. Almost half of them thought they knew many techniques for redirecting players' negative behavior during the game, and one in three could not answer this question. Among the 116 respondents, $61.2 \%$ agreed with the statement that it happened that the match was out of their control. The referees evaluating their interactions with the players in the dimension of instructing, mostly agreed that while refereeing, they gave the players information about the rules of the game or helped with their interpretation, while every third referee presented the correct execution of a technical element (e.g. throw-in). Regarding the statements about communicating the values of the sport to the athletes and explaining their decisions, the referees responded in the most varied way $(\mathrm{SD}=0.82)$. Such behavior was confirmed by almost half of the respondents. The last dimension examined concerned the quality of communicating. While the majority of referees felt that their verbal messages were always clear and explicit, almost $45 \%$ of them admitted that there were times when the players asked them what had happened and what the decision was. The average overall rating of the communicating dimension is also due to the fact that only half of the referees surveyed admitted to mistakes on the field. 


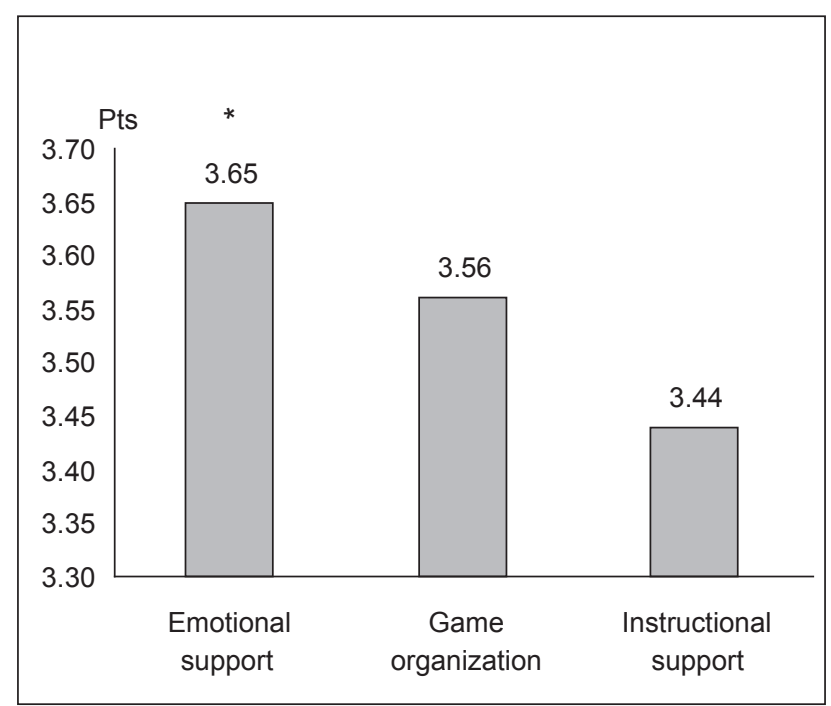

Figure 1. Mean $( \pm \mathrm{SD})$ ratings of the quality of referee-player interactions in individual domains $(\mathrm{n}=116)$ * significantly $(p<0.05)$ higher than Instructional support domains (Friedman's ANOVA followed by Wilcoxon's signed ranks test).

Figure 1 shows the average referees' ratings for each domain. After conducting a test to examine the significance of differences between referees' self-assessments in the three domains of their educational function $(\mathrm{Chi}=11.103$; $\mathrm{p}=004)$, differences were found only between emotional support and instructing $(\mathrm{Z}=-3.611 ; \mathrm{p}<0.001)$. The differences are that referees rated their educational interactions with players significantly higher in the domain of emotional support $(\bar{x}=3.65 ; \mathrm{SD}=0.49)$ than the instructing provided $(\bar{x}=3.44 ; \mathrm{SD}=0.55)$.

The study aimed to investigate whether refereeing experience was a determinant of the self-reported quality of interactions with players. It was hypothesized that more experienced referees would declare the higher quality of interactions in terms of the highlighted domains. The results of the test indicated that there were no statistically significant differences in the referees' self-assessment between the groups distinguished by experience in the domains of Emotional support and Game organization. In contrast, these differences were found to be significant for the third domain $(Z=-2.726 ; p<0.05)$. Less experienced referees rated the quality of their educational interactions in the Instructional support domain higher than those more experienced. The value of Cronbach's alpha of 0.703 obtained from the analyses indicates sufficient similarity of self-assessments discussed in the study.

\section{Discussion}

The present study postulated that the tasks of a referee include not only enforcing the rules of the game and its efficient organization. Due to the educational aspect of children and youth sports, the referee should also be a good educator, making sure that the sports field is a place of positive experiences for the players. Therefore, the referees were asked how they rated their interactions with players in terms of emotional support, game organization, and instructional support. Taking into account that referees' answers to the questionnaire items are declarative and their actual behavior on the pitch may differ from the declarations, a research tool was prepared to compare the obtained results with the results of direct observations of referees from the same regional football association and refereeing the matches of the same age category (Firek, Płoszaj \& Czechowski, 2020). One of the aims of the study was to examine whether referees' statements about their interactions with players are influenced by experience. This is expressed in the first hypothesis assuming that more experienced referees rate their competencies higher in all the distinguished domains of the educational function of referees compared to those less experienced. Justification for this hypothesis was, among other things, the findings of MacMahon et al. (2007) and Dosseville et al. (2013). In light of their research, a referee's experience has a significant impact on his or her work performance in many ways. This is also indicated by the research conducted among players (Simmons, 2008). Less experienced referees are perceived by the players as worse and thus are given less respect. This makes inexperienced referees have less potential for educational influence on players. However, the results of the study indicate that the referee's experience 
was not a factor influencing their self-assessment in this aspect. Neither in the domain of Emotional support nor Game organization was there any differences observed in the referees' self-assessment between the groups distinguished by experience. Therefore, the first hypothesis was not confirmed. Similar results were also reported during direct observation of the referees (Firek et al., 2020).

\section{Emotional support}

Referees are aware that they must build positive relationships with players is one of their key competencies (Morris \& O'Connor, 2017). This seems to be particularly important in the area of children's and youth sports, as all entities involved in the organization of sports competition for the youngest players should do as much as possible to make the match a source of joy, satisfaction, and positive experiences for the players (Visek, Achrati, Manning, McDonnell, Harris \& DiPietro, 2015; Witt \& Dangi, 2018). Building a positive climate during matches also aims to reduce the phenomenon of children giving up sport prematurely (Côté \& Hancock, 2016). In our study, referees rated their interactions in terms of Emotional support higher than their interactions with athletes in the other two domains. However, this difference was significant only in relation to the Instructional support domain. These results do not allow a positive verification of the second hypothesis assuming that the quality of the referee-player interactions self-assessed by referees will be the highest in the domain of Game organization. This means that the referees perceive themselves on the field as caring for a positive climate during the game and meeting the expectations and needs of the children. These results contrast with the study by Firek et al. (2020). Direct observation of referees' work in this area indicates that this is the area in which referees perform the worst. Indeed, the referees were rated higher in the domain of Game organization. Where did this discrepancy come from? This is likely to be due to the fact that the tool for direct observation of the educational function of the referee (R-PIASS) presents a model of an ideal referee-educator and compares it with the actual behavior of referees on the field. Perhaps the referees used a different measure to assess their behavior. Referees might not be fully aware of the demands placed on them to provide emotional support to players during the game. They need to be reminded of this as the atmosphere created by adults during the game makes children perceive the sporting event more positively (Stuart \& Ebbeck, 1995; Guivernau \& Duda, 2002). As the only adult person on the pitch, the referee should also take care of the climate of the game, because his or her behavior affects the mental state of the players (Bar-Eli et al., 1995). A good referee can recognize the emotional states of the players, take a child's perspective (Eisenberg, Carlo, Murphy \& Van Court, 1995), and adjust their behavior accordingly (Dosseville, Laborde, \& Garncerzyk 2013; Dosseville, Laborde \& Bernier, 2014).

\section{Game organization}

In the normative model of the referee-educator presented in R-PIASS (Płoszaj, Firek \& Czechowski, 2020), the referee is required to know and use methods and techniques to prevent and redirect negative player behavior. The study by Arthur-Banning et al. (2007) shows that referees demonstrating such skills were better able to organize the game and reinforce positive behavior than referees without such skills. Furthermore, Mascarenhas et al. (2005) argued that if we want to educate through sport, aggression should be avoided as much as possible. The present study, only half of the referees reported knowing and being able to use techniques to redirect negative behavior, with verbal messages (e.g., warnings, admonitions) being the predominant method. The referees rated themselves higher in proficiency, i.e. the ability to organize the game smoothly and without unnecessary interruptions, and the referee's preparation for refereeing, although the overall self-assessment score in the Game organization domain is average. It is therefore also a space in which referees can improve to better perform their educational function. Furthermore, in the research involving direct observation of referees (Firek, Płoszaj \& Czechowski, 2020), Game organization was the highest-rated domain, meaning that the referees are well prepared to officiate the game, have the right uniforms and equipment; when they officiate, the game is smooth and the players know what to do. It is worth noting that the scores in this domain in the compared studies were definitely lowered by worse competencies in managing behavior. From a pedagogical point of view, it is worth taking care of these competencies, because as MacMahon et al. demonstrated (2008), refereeing means solving problem situations, not just making decisions mechanically. The events on the field often force the changes in refereeing style and its adjustment to the atmosphere of the match and the players' behavior (Mascarenhas et.al., 2005). Andersson (2019) expanded the tasks of referees to include controlling not only players but also coaches and referees. In this respect, the referee can be considered the main creator of the sports spectacle. 


\section{Instructional support}

In addition to emotional support, the official should also aim to meet the cognitive needs of the players by providing instructional support. Among the three types of referee, McMahon et al. (2015) enumerated the referee-teacher, automatically attributing the educational function of imparting knowledge and shaping skills to them. Arthur-Banning et al. (2007) argued that referees forget that they are supposed to be teachers of the game. The referee-teacher should justify their decisions as to avoid a sense of uncertainty from the players and to avoid future violations of the rules. Berkowitz and Grych (1998) also wrote about the benefits of instructing young athletes. In the present study, referees in the Instructional support domain rated themselves lowest. A study by Firek et al. (2020) indicated that referees in this domain do not perform the worst. Perhaps the referees' low self-assessment in terms of instructional support is caused by their belief that they lack adequate communication skills or their awareness of not taking advantage of all on-field situations that are conducive to teaching the rules of the game and the value of sport. Such beliefs of referees are supported by the research of Andersson (2019), who indicates that referees realize that by refereeing the game, communicating their decisions, and instructing the players, they influence their multilateral development.

\section{Conclusions}

A comparison of the referees' self-assessment with their direct observations reveals significant discrepancies. Referees declare high quality in terms of emotional support given to the players, while direct observation shows the opposite. Therefore, the main conclusion of the research is the postulate to introduce pedagogical and psychological issues into the referee training. This is a very important postulate because it extends the current and traditional tasks of the referee on the pitch. One can expect resistance from referees based on the fact that the referees are already under a heavy workload. However, if we agree with the common assumption about the educational function of sport, a natural consequence is that the organizers of sporting events for young athletes are obliged to take care of an appropriate educational climate. To date, the concept of the double-goal coach and many models of positive sports parenting have been developed. It should not be forgotten, however, that the effectiveness of educational activities in sport is determined by the cooperation of coaches, parents, and the referee. These interactions have to face barriers and the inability to tackle deeply embedded cultural norms that allow aggressive behaviour towards referees (Cleland, O'Gorman \& Webb, 2018). Parents-referees conflicts seem to be particularly disadvantageous in children and youth sport (Nutt, 2006; Dell, Gervis \& Rhind, 2016). If we add to the inappropriate interactions between coaches, parents and referees the general lack of support from sports associations, insufficient practical training and inability to deal with stress, we will get a list of factors causing referees to leave the profession. Therefore, there is a need for better training and support of referees (Webb 2014). There are more and more opinions in the literature that the referee is the person whose behavior is not irrelevant to the educational function of sport. So far, referees have declared their awareness of the educational function but they did not know how to perform this function. The developed normative models of the referee-educator are needed to fill the missing link in the process of education through sport. This link is the referee, who should cooperate with both coaches and parents to provide an educational environment for children and young people.

\section{Ethics approval and informed consent}

The research was approved by the Research Bioethics Commission of the Józef Piłsudski University of Physical Education in Warsaw (SKE 01-10-2020).

\section{Competing interests}

The authors declare no conflict of interest.

\section{Funding}

This research was funded by Social and Humanistic Research School of Physical Culture (Research School No. 2) of the Józef Piłsudski University of Physical Education in Warsaw.

\section{Acknowledgments}

We thank Mr. Jan Jechna for his help in collecting research data among football referees. 


\section{References}

Andersson, E. (2019). A referee perspective on the educational practice of competitive youth games: exploring the pedagogical function of parents, coaches and referees in grassroots soccer. Phys. Educ. Sport Pedagogy, 24(6), 615-628, DOI: 10.1080/17408989.2019.1652806.

Arthur-Banning, S.G., Paisley, K. \& Wells, M.S. (2007). Promoting Sportsmanship in Youth Basketball Players: The Effect of Referees' Prosocial Behavior Techniques. J. Park Recreat. Adm. 25, 96-114.

Bar-Eli, M., Levy-Kolker, L., Pie, J.S. \& Tenenbaum, G. (1995). A crisis-related analysis of perceived referees' behavior in competition. J. Appl. Sport Psychol. 7, 63-80, DOI: 10.1080/10413209508406301.

Battistich, V., Solomon, D., Watson, M. \& Schaps, E. (1997). Caring school communities. Educ. Psychol. 32, 137-151, DOI: $10.1207 / \mathrm{s} 15326985 \mathrm{ep} 3203 \_1$.

Bengoechea, E.G., Strean, W.B. \& Williams, D.J. (2004). Understanding and promoting fun in youth sport: Coaches' perspectives. Phys. Educ. Sport Pedagogy, 9, 197-214, DOI: 10.1080/1740898042000294994.

Birchwood, D., Roberts, K. \& Pollock, G. (2008). Explaining differences in sport participation rates among young adults: Evidence from the South Caucasus. European Physical Education Review, 14(3), 283-298, DOI: https://doi.org/10.1 177\%2F1356336X08095667.

Boxer, P., Tisak, M.S. \& Goldstein, S.E. (2004). Is it Bad to be Good? An Exploration of Aggressive and Prosocial Behavior Subtypes in Adolescence. J Youth Adolesc. 33(2), 91-100, DOI: 10.1023/B:JOYO.0000013421.02015.ef.

Cipriano, P., Martins,P. ,Duarte, R. ,Preto, L., Peixoto, C. \& Moreira, M. (2020). Investigation on Soccer Referees: A Narrative Review. Polish J. Sport Tour., 26(3), 20-28, DOI: 10.2478/pjst-2019-0016.

Cleland, J., O'Gorman, J. \& Webb, T. (2018) Respect? An investigation into the experience of referees in association football. International Review for the Sociology of Sport, 53(8), 960-974, DOI: 10.1177\%2F1012690216687979.

Collins, K. \& Barcelona, R. (2018). Keep 'Em Playing: Strategies for Building Positive Sport Experiences. A Journal for Physical and Sport Educators, 31(5), 8-14, DOI: 10.1080/08924562.2018.1490231.

Côté, D. \& Hancock, J. (2016). Evidence-based policies for youth sport programs. Int. J. Sport Pol. Politics. 8, 51-65, DOI: $10.1080 / 19406940.2014 .919338$.

Cronin, L.D. \& Allen, B.A. (2015). Developmental Experiences and Well-Being in Sport: The Importance of the Coaching Climate. Sport Psychol. 29(1), 62-71, DOI: 10.1123/tsp.2014-0045.

Dell, C., Gervis, M. \& Rhind, D. (2016). Factors influencing soccer referee's intentions to quit the game. Soccer \& Society, 17(1), 109-119, DOI: 10.1080/14660970.2014.919275.

Domingues, M. \& Gonçalves, C.(2013). The Role of Parents in Talented Youth Sport. Does Context Matter? Polish J. Sport Tour., 20(2), 117-122, DOI: 10.2478/pjst-2013-0011.

Dosseville, F., Laborde, S. \& Bernier, M. (2014). Athletes' expectations with regard to officiating competence. Eur. J. Sport Sci. 14, 448-455, DOI: 10.1080/17461391.2012.713006.

Dosseville, F., Laborde, S. \& Garncerzyk, C. (2013). Current research in sports officiating and decision-making. In C. Mohiyeddini (Eds.), Contemporary Topics and Trends in the Psychology of Sports (pp. 13-38). New York, NY, USA: Nova Publishers.

Eisenberg, N., Carlo, G., Murphy, B. \& Van Court, P. (1995). Prosocial development in late adolescence: A longitudinal study. Child Dev. 66, 1179-1197.

Firek, W., Płoszaj, K. \& Czechowski, M. (2020). Pedagogical function of referees in youth sport: assessment of the quality of referee-player interactions in youth soccer. Int J Environ Res Public Health, 17(3), 1-15, DOI: $10.3390 \% 2$ Fijerph 17030905 .

Friman, M., Nyberg, C. \& Norlander, T. (2004). Threats and aggression directed at soccer referees: An empirical phenomenological psychological study. Qual. Rep. 9, 652-672, DOI: 10.46743/2160-3715/2004.1908.

Fruchart, E. \& Carton, A. (2012). How do amateur soccer referees destabilize a match? Psicológica, 33, 435-449.

Fry, M.D. (2010). Creating a Positive Climate for Young Athletes from Day 1. J. Sport Psychol. Action, 1, 33-41, DOI: 10.1080/21520704.2010.518224.

Galily, Y., Leitner, M.J. \& Shimion, P. (2013). The effects of three Israeli sport programs on attitudes of Arabs and Jews toward one another. Aggression, Conflict and Peace Research, 5, 243-258, DOI: 10.1108/JACPR-02-2013-0006.

Giulianotti, R. \& Numerato, D. (2017). Global sport and consumer culture: An introduction. Journal of Consumer Culture, 18(2), 229-240, DOI: 10.1177\%2F1469540517744691.

Guivernau, M. \& Duda, J.L. (2002). Moral atmosphere and athletic aggressive tendencies in young soccer players. $J$. Moral Educ. 31, 67-85, DOI: 10.1080/03057240120111445. 
Hardwood, C.G. \& Knight, C.J. (2015). Parenting in Youth Sport. A position paper on parenting expertise. Psychol. Sport Exerc. 16, 24-35, DOI: 10.1016/j.psychsport.2014.03.001.

Horn, T.S. (2008). Coaching effectiveness in the sport domain. In T.S. Horn (Eds.), Advances in sport psychology (3rd Ed.) (pp. 239-268). Champaign, IL: Human Kinetics.

Isidori, E., Müller, A. \& Kaya, S. (2012). The Referee as Educator: Hermeneutical and Pedagogical Perspectives. Phys. Cult. Sport, Stud. Res. LVI, 5-11, DOI: 10.2478/v10141-012-0023-2.

Jones, C. (2005). Character, virtue and physical education. Eur. Phys. Educ. Rev. 11(2), 139-151, DOI: $10.1177 \% 2 \mathrm{~F} 1356336 \mathrm{X} 05052893$.

Keim, M. (2012). Developing peace through community sport in multi-ethnic South African contexts. In R.J. Schinke \& S.J. Hanrahan (Eds.), Sport for development, peace and social justice (pp. 9-22). Morgantown, WV: Fitness Information Technology.

Lavay, B.W., French, R. \& Henderson, H.L. (2016). Positive behavior management in physical activity settings. United States of America: Human Kinetics.

Lehman, D.R. \& Reifman, A. (2001). Spectator influence on basketball offciating. J. Soc. Psychol. 127, 673-675.

Lenartowicz, M. \& Mosz, J. (2018). Stadiony i widowiska. Spoleczne przestrzenie sportu. Warszawa: Wydawnictwo naukowe Scholar.

Lenartowicz, M. (2016). Family leisure consumption and youth sport socialization in post-communist Poland: A perspective based on Bourdieu's class theory. International Review for the Sociology of Sport, 51(2), 219-237, DOI: $10.1177 \% 2 \mathrm{~F} 1012690213516619$.

Light, R.L. \& Harvey, S. (2015). Positive pedagogy for sport coaching. Sport Educ. Soc. 2, 1-17, DOI: 10.1080/13573322.2015.1015977.

MacMahon, C. \& Plessner, H. (2008). The sports offcial in research and practice. In D. Farrow, J. Baker \& C. MacMahon (Eds.), Developing Sport Expertise: Researchers and Coaches Put Theory into Practice, London, UK: Routledge.

MacMahon, C., Helsen, W.F., Starkes, J.L. \& Weston, M. (2007). Decisionmaking skills and deliberate practice in elite association football referees. J. Sports Sci. 25, 65-78, DOI: 10.1080/02640410600718640.

MacMahon, C., Mascarenhas, D., Plessner, H., Pizzera, A., Oudejans, R.R.D. \& Raab, M. (2015). Sports Offcials and Offciating: Science and Practice. New York, NY, USA: Routledge/Taylor \& Francis Group.

Mageau, G.A., Vallerand, R.J. (2003). The coach-athlete relationship: A motivational model. Journal of Sports Science, 21, 883-904, DOI: 10.1080/0264041031000140374.

Mascarenhas, D.R., Collins, D. \& Mortimer, P. (2005). Elite Refereeing Performance: Developing a Model for Sport Science Support. J. Sport Psychol. 19, 364-379, DOI: 10.1123/tsp.19.4.364.

Morris, G. \& O'Connor, D. (2017). Key attributes of expert NRL referees. J. Sports Sci. 35, 852-857, DOI: 10.1080/02640414.2016.1194524.

Nutt, G. (2006). Referees. In. Brackenridge, C., Pitchford, A., Russell, K. \& Nutt G. (Eds.), Child Welfare in Football: An Exploration of Children's Welfare in the Modern Game (pp. 96-109). London: Routledge, DOI: 10.4324/9780203099063.

Pianta, R.C., Hamre, B.K. \& Mintz, S.L. (2012). The CLASS-Upper Elementary Manual. Charlottesville, VA, USA: University of Virginia.

Płoszaj, K., Firek, W. \& Czechowski, M. (2020). The referee as an educator: assessment of the quality of referee-players interactions in competitive youth handball. Int J Environ Res Public Health. (17)11, 1-19, DOI: 10.3390/ijerph17113988.

Romani, Q.A. (2019). Parental behaviour and children's sports participation: Evidence from a Danish longitudinal school study. Sport Educ. Soc. 25(3), 332-347, DOI: 10.1080/13573322.2019.1577235.

Schinke, R.J. \& Hanrahan, S.J. (2012). Sport as a possible intervention: An introduction. In R.J. Schinke \& S J. Hanrahan (Eds.), Sport for development, peace and social justice (pp. 1-8). Morgantown, WV: Fitness Information Technology.

Simmons, P. (2008). Justice, culture and football referee communication. Paper presented to the I-Come International Communication and Media Conference. Kuala Lumpur, Malaysia: University Utara.

Slack, L.A., Maynard, I.W., Butt, J. \& Olusoga, P. (2013). Factors underpinning football officiating excellence: perceptions of English Premier League referees. J. Appl. Sport Psychol. 25, 298-315, DOI: 10.1080/10413200.2012.726935.

Strandbu, Å., Stefensen, K., Smette, I. \& Sandvik, M.R. (2019). Young people's experiences of parental involvement in youth sport. Sport Educ. Soc. 24, 66-77, DOI: 10.1080/13573322.2017.1323200.

Straub, G. (2019). Parental (over-)ambition in competitive youth sport: A multi-theoretical approach. Ger. J. Exerc. Sport Res. 49, 1-10, DOI: 10.1007/s12662-018-0561-9. 
Stuart, M.E. \& Ebbeck, V. (1995). The influence of perceived social approval on moral development in youth sport. Pediatr. Exerc. Sci. 7, 270-280, DOI: 10.1123/pes.7.3.270.

Telama, R., Yang, X., Viikari, J., Välimäki, I., Wanne, O. \& Raitakari, O. (2005). Physical activity from childhood to adulthood: A 21-year tracking study. American Journal of Preventive Medicine, 28(3), 267-273, DOI: 10.1016/j. amepre.2004.12.003.

Theodoulides, A. (2003). I Would Never Personally Tell Anyone to Break the Rules, But you can Bend Them: Teaching Moral Values Through Team Games. European Journal of Physical Education, 8(2), 141-59, DOI: 10.1080/1740898030080204.

Thompson, J. (2013). The Double-Goal Coach: Positive Coaching Tools for Honoring the Game and Developing Winners in Sports and Life. New York: HarperCollins Publishers.

Tiessen, R. (2011). Global Subjects or Objects of Globalisation? The promotion of global citizenship in organisations offering sport for development and/or peace programmes. Third World Quarterly, 32(3), 571-587, DOI: 10.1080/01436597.2011.573946.

Visek, A., Achrati, S.M., Manning, H., McDonnell, K., Harris, B.S., \& DiPietro, L. (2015). The fun integration theory: Towards sustaining children and adolescents sport participation. J. Phys. Act. Health, 12, 424-433, DOI: 10.1123/ jpah.2013-0180.

Webb, T. (2014). The emergence of training and assessment for referees in association football: Moving from the sidelines. The International Journal of the History of Sport, 31(9), 1081-1097, DOI: 10.1080/09523367.2014.905545.

Wheeler, S. (2012). The significance of family culture for sports participation. International Review for the Sociology of Sport, 47(2), 235-252, DOI: 10.1177\%2F1012690211403196t.

Witt, P.A. \& Dangi, T.B. (2018) Why Children/Youth Drop Out of Sports. J. Park Recreat. Adm. 36, 191-199, DOI: 10.18666/JPRA-2018-V36-I3-8618.

Woolfolk Hoy, A. \& Weinstein, C.S. (2006). Student and Teacher Perspectives on Classroom Management. Abingdon: Routledge.

This is Open Access article distributed under the terms of CC-BY-NC-ND 4.0 International License. 